\title{
Fingering the brain's past
}

\section{Minds Behind the Brain: \\ A History of the Pioneers and Their Discoveries}

by Stanley Finger

Oxford University Press: 2000. 384 pp.

$\$ 35, £ 24.99$

\section{Ian Glynn}

Six years ago, Stanley Finger published his monumental Origins of Neuroscience (Oxford University Press), nearly two kilograms of double-column format, profusely illustrated and fully referenced, with a cast of some 900 involved in events extending over more than four millennia. Inevitably, with such a wide scope, much had to be omitted or condensed. Even the principal characters held the stage for too short a time to become fully rounded. The book had an encyclopaedic quality, and has, I suspect, been much more often dipped into repeatedly than read from cover to cover hence the need for another and different book on the same general topic.

The immediate stimulus for Minds Behind the Brain, Finger tells us, came from the students who attended his lectures at Washington University, St Louis, Missouri. They wanted to know more about the brain pioneers "as real people"; they wanted to see more fully what led to their discoveries, and to understand "the ramifications of their insights ... knowing the year of a landmark and a 'beard' was not enough". And Finger himself wanted space to look at the scientific literature in a social context. To achieve these aims he has had to prune his cast list drastically. $\mathrm{He}$ started, he tells us, by choosing a dozen highly influential players; but this figure waxed and waned, settling at 19 , with a sizeable supporting cast who provide the background and illustrate the consequences the achievements of the principal characters.

And the recipe works. Finger's erudition is remarkable. Even the characters we thought we knew about appear in a new light. René Descartes' conviction that animals lack consciousness seems even more remarkable when we learn not only that he had a pet dog, but also that he was extremely fond of it. We know about Galen's successes, so it is refreshing to hear of one of

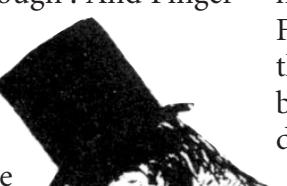

his failures - an attempt to increase the efficiency of leeches, by clipping their tails so that they could draw more blood, had to be abandoned when a sharp rise in leech mortality led to an increase in price. Those of us who have been raised on Michael Foster's History of Physiology have to revise (favourably) our views of both the character and achievements of the seventeenth-century anatomist and physician Thomas Willis. We know about Leyden jars, and we know that the Abbé Nollet, in eighteenth-century Paris, did party tricks with static electricity; but we may be surprised to learn that it was Nollet who coined the phrase 'Leyden jar', and that he once used one to make a 900-foot line of Carthusian monks jump en masse. Conversely, we might be astonished to discover that Franz-Joseph Gall, the founder of phrenology, never used the word phrenology.

But my favourite improbable story is of the physiologist Charles Sherrington as an immunologist. He and a colleague had been inoculating horses with small doses of diphtheria toxin in the hope that the animals would make a useful antitoxin. Hearing one night that his eight-year-old nephew had contracted diphtheria, he dashed down to Sussex with a flask of antiserum from one of the horses and, on being told by the family physician that the boy was expected to die within the next few hours, administered the antiserum. To the surprise of the physician, and to Sherrington's delight, the boy recovered within a day.

Even historical characters whom most of us would never have associated with the history of neuroscience are caught in Finger's penetrating spotlight. John Wesley, the founder of Methodism, wrote a popular book recommending electrical treatment for disorders of the nervous system. Emanuel

Swedenborg, after he had retired from being director of Swedish mines and before he experienced the visions that led to his reinterpretation of Christianity, was fascinated by the idea that different functions of the body were controlled by different areas of the cerebral cortex. Basing his arguments mainly on the observations of others, he reached original and important conclusions which, unfortunately, did not become widely known. In the next century, both Percy Bysshe Shelley and Mary Shelley were fascinated by 'galvanism'; and Shelley inadvertently electrocuted the family cat while trying to use electricity to treat his sister's skin disorder.

Dressed for the job: nineteenth-century neurologist Jean-Martin Charcot at work.
Inevitably, the draconian slimming down of the cast means that the choice of those who are left must sometimes appear arbitrary. In discussing localization of function in the cerebral cortex, Finger mentions Swedenborg, Gall, Paul Broca, Carl Wernicke, James Ferrier and Eduard Hitzig, but says nothing about Salomon Henschen, Louis Verrey, Jules Déjerine or Harvey Cushing; Wilder Penfield is mentioned only very briefly. The discovery of chemical transmission at synapses is described at length, but the long history of the discovery of the nature of transmission along nerve fibres is lightly skimmed over. These are not serious criticisms. The book is designed as a series of fascinating excursions into the past, not an all-inclusive grand tour. Each of us may miss favourite characters and topics; but we are rewarded by the extra time that Finger can devote to the people and topics he chooses to write about.

Ian Glynn is at Trinity College, University of Cambridge, Cambridge CB2 1TQ, UK.

\section{Before the great binary divide}

\section{Ingenious Pursuits: Building the} Scientific Revolution

by Lisa Jardine

Doubleday: 1999. 480 pp. \$35, £25

\section{Bruce Mazlish}

The notion of 'two cultures' - art and science - has taken on mythical status. The great binary divide still possesses our imagination in spite of an original misunderstanding - C. P. Snow was less concerned with the break between science and literature than with a policy implication, that the lack of training in science could hamper economic development. The divide continues even though this leaves no room for a third culture, that of the social sciences, and despite the fact that the rise of multiculturalism has claimed to make the two-culture formula obsolete.

There are numerous reasons for the persistence of the common idea of two cultures. Many natural scientists are happy to see their subjects reaffirmed as being separate, that is, not contaminated by subjectivity from the soft humanities. Many humanists welcome the divorce as underlining their difference from the cold, calculating, 'inhuman' scientists. Either faction could appeal to much of the history of science as it was written in the period prior to the past few decades. Indeed, until recently, and still often today in practice, the natural and the human sciences have been treated, without further discussion, in a more or less compartmentalized manner. Snow, in contrast, at least put the subject on the table, 
albeit in rather dramatic fashion. It is to the credit of Lisa Jardine, professor of Renaissance studies at the University of London, that her latest book demonstrates (although does not formally argue) the continuity, if not unity, of the two cultures.

Jardine's subject is seventeenth-century, everyday scientific life. Here there was no opposition between natural science and art and literature; rather, they were entwined. Robert Hooke had studied portrait painting before he published Micrographia, with its wonderful illustrations. Christopher Wren practised architecture with an eye to his buildings, such as St Paul's cathedral, being used for astronomical observations. William Harvey's anatomy was intimately intertwined with its representations in engraved plates. A look at the roster of the Royal Society, where a John Locke sat next to a Robert Boyle, confirms the lack of boundaries as we know them.

Jardine's canvas is broad. She ties together the 1680 comet with the construction of the Royal Observatory at Greenwich, and links both with the needs of war and the nation. Mapping is connected to the coming of clockwork, and the exact measurement of small intervals so essential to the development of science at large, and especially to the solution of the problem of longitude. Drainage, land reclamation, fortifications, the air pump, the transfusion of blood, the use of diving machines, the collection of specimens - all are to be found here interrelating in sometimes obvious and other times strange ways. Much of what has been called the 'Scientific Revolution' is to be found here.

In many ways it is a coffee-table book (oddly enough, this is a phrase Jardine uses for Hooke's great work), for it is lavishly illustrated, with many coloured plates. It is primarily based on secondary work, as it should be, for it is a work of synthesis, placing mostly known material in new juxtapositions. Yet it rises towards originality in offering an "anthropology of science" that depicts the seventeenth-century sciences in ordinary, practical life, with practitioners clamouring for priority and notice, often filled with spite, eager for advancement. It is an application of Bruno Latour to an earlier period.

In her own life, Jardine exemplifies the personal aspect of scholarly or scientific work. As the daughter of Jacob Bronowski, whom many identify as the real source of the notion of the two cultures and its solution - certainly its exemplification and to whom the book is dedicated, she carries on in his spirit in exemplary fashion.
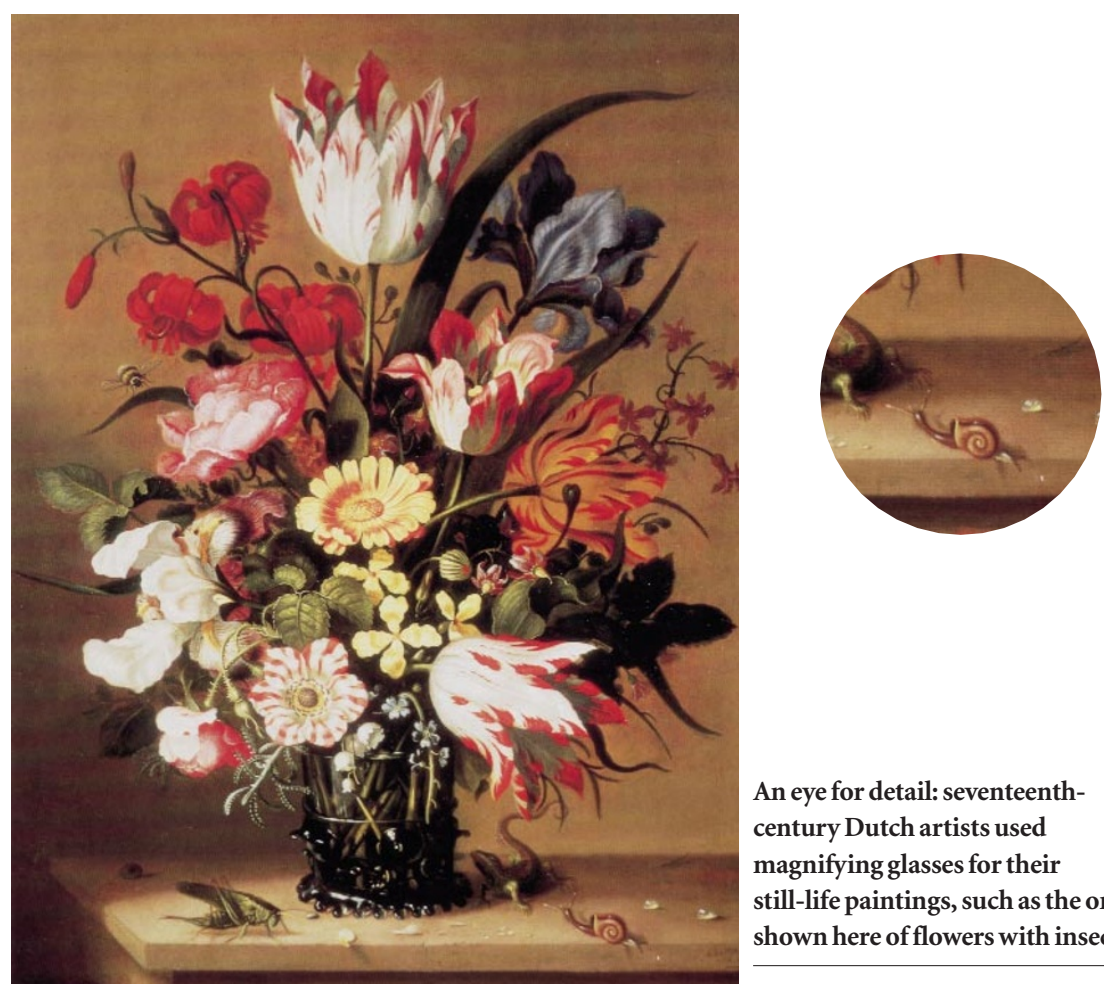

An eye for detail: seventeenthcentury Dutch artists used magnifying glasses for their still-life paintings, such as the one shown here of flowers with insects.

Her own starting point is the situation today, where the natural sciences are under attack for their nefarious consequences. Fittingly, the first sentence of her book refers to the publication in Nature of the 1997 report on the cloning of Dolly the sheep, and then goes on to the subsequent attacks on human hubris in seizing upon such God-like powers. The epilogue concerns The Double Helix (Penguin, 1999), and its account of scientific genius and personal ambition. Indirectly, then, Jardine's book is as much about contemporary science as it is about its seventeenth-century antecedents.

There are caveats. The illustrations are illuminating, but are rarely tied in significantly to the text. And why are the colour plates disconcertingly repeated in black and white (certainly running up the cost of the book)? Publishing data on cited material are either missing or hard to find. The chronology is occasionally confusing. The emphasis is on English material, with some attention to the Dutch and French, although the book's stated thesis is on the international nature of science.

The dark shadows of science are relegated to the far corners, only occasionally allowed to peep through with regard to vivisection or military affairs. This is a generally sunny picture of science (one, I confess, I myself lean towards, although I believe more attention should be paid to the dark side as well).

Putting such caveats aside, one must applaud Jardine's achievement. In the same mode as her highly successful Worldly Goods (Papermac, 1997), she has sought to make scholarly research available to a broad public. In 1672, as Jardine tells us, Henry Oldenburg complimented Isaac Newton on his "ingenuity". I am moved to describe Jardine's own work as 'ingenious'.

Bruce Mazlish is in the History Faculty,

Massachusetts Institute of Technology, Cambridge, Massachusetts 02138, USA.

\section{III-served inventions}

\section{The Greatest Inventions of the}

Past 2000 Years

edited by John Brockman

Simon \& Schuster: 2000. 192 pp. \$22

\section{David Jones}

An editor should be respected, even feared, maybe even disliked, by his contributors. His job is to dock their prolixities, unify their styles, and force them to conform to a consistent and clearly defined vision of the work in hand. It is no job for a democrat

The trouble that can result from democratic, permissive editing is sadly illustrated by The Greatest Inventions of the Past 2000 Years. John Brockman invited a coterie of "today's leading thinkers" to pen - or rather to e-mail - their thoughts on this topic. They seem to have had a lot of fun with it, e-mailing chatty ideas back and forth. Brockman then assembled 109 of the resulting messages into this book. 